\title{
A New, Rapid, Cost-Effective, Easy and Validated RP-HPLC Method for Determination of Antiviral (Sofosbuvir) in Bulk Forms
}

\author{
Yasir Mehmood $^{1}$, Ikram Ullah Khan ${ }^{* 1}$, Yasser Shahzad ${ }^{2}$, Syed Haroon Khalid ${ }^{1}$, \\ Sajid Asghar ${ }^{1}$, Abid Mehmood Yousaf ${ }^{2}$, Talib Hussain ${ }^{2}$, Muhammad $\operatorname{Irfan}^{1}$ and \\ Ikrima Khalid $^{1}$ \\ ${ }^{1}$ Department of Pharmaceutics, Faculty of Pharmaceutical Sciences, \\ Government College University Faisalabad, Pakistan. \\ ${ }^{2}$ Department of Pharmacy, COMSATS University Islamabad, Lahore Campus, Lahore, Pakistan. \\ *Corresponding Author Email: ikramglt@gmail.com \\ Received 09 May 2018, Revised 04 December 2018, Accepted 30 June 2019
}

\begin{abstract}
A simple, specific, accurate and economic reverse phase liquid chromatographic method was developed for the estimation of Sofosbuvir in all polymorphic form. Mobile phase contains acetonitrile and $0.05 \mathrm{M}$ ammonium acetate $(\mathrm{pH} 7.6)$ in ratio of 50:50 (v/v). A logarithmic calibration curve was plotted from $10 \mu \mathrm{gmL}^{-1}$ to $60 \mu \mathrm{gmL}^{-1}(\mathrm{r}=0.9989)$ for sofosbuvir, with the limit of detection (LOD) and the limit of quantification (LOQ) of $0.245 \mu \mathrm{gmL}^{-1}$ and $0.816 \mu \mathrm{gmL}^{-1}$, respectively. The developed method was highly validated and practiced for the assurance of sofosbuvir raw materials with acceptable and non-objectionable accuracy and precision results (recovery $99-102 \%, \mathrm{RSD}<1.2 \%, \mathrm{n}=3$ ). Zero significant difference (t-test) was obtained between the overall results of the developed RP-HPLC method.
\end{abstract}

Keywords: Calibration, Chromatography, Developed, Accuracy, Sofosbuvir.

\section{Introduction}

A serious health concern these days is the contamination of Hepatitis C virus (HCV) with roughly 170-180 million infections in population around the world [1, 2]. HCV infected patients face the hazards of lethal complexities which could result in liver failure (decomposed liver disease), cirrhosis, hepatocellular carcinoma and urgency for liver transplantation $[3,4]$. Just before the ultimate current advancements of remedies for six primary genotypes and subdivisions of $\mathrm{HCV}$, various problematic standards of care (SOC) with negligible sustained virologic response (SVR) were accessible as distinct consolidation of pegylated alpha interferon, ribavirin, interferon, boceprevir and telaprevir; nonetheless, above mentioned included different poisonous as well as unfavourable reactions, with meagre sustainability
[5-9]. Sofosbuvir (SFV), also known as GS-7977, is a nucleotide analogue polymerase which prevents non-structural protein (NS-5B) and is currently the most innovative, powerful and free from harm prodrugs, with huge SVR rates and is applied by mixing alongside other medicinal products for the medication of $\mathrm{HCV}$ infections [10, 11]. The goal of HCV remedy is to accomplish SVR which is characterized as HCV-RNA $<15 \mathrm{IU} / \mathrm{mL}, 12$ or 24 weeks subsequently the consummation of antiviral therapy. Generally, SVR was estimated after the end of 24 weeks of medication. However, as a result of harmony between SVR 12 and SVR 24, the latest propositions approves the 12 weeks based assessment [12]. 
HPLC, through current analysis explains the progress and affirmation of a rational evaluation technique for SFV material. The isocratic approach was used together with a reverse phase C-18 column, $0.05 \mathrm{M}$ ammonium acetate $(\mathrm{pH}$ 7.6) and acetonitrile in ratio of 50:50 (v/v), and a 10 min run time, in accordance with the criterion mentioned in USP 29 (2006) and ICH (2005). The approach used presents an edge over different methods explained in the documentation.

\section{Materials}

99.8\% pure reference standard of sofosbuvir was purchased from Pharmagen pharmaceuticals Lahore, Pakistan, HPLC grade acetonitrile (Dae-Jung, Korea) and ammonium acetate were purchased from Sigma-Aldrich (Germany). Other chemicals were of analytical grade.

\section{Instrumentation}

A Shimadzu HPLC system LC-20AB high-pressure binary gradient pump, CBM-20Alite system controller, and a seal wash pump (LC20AD) inside the solvent delivery unit. Promosil C18 series columns (Agela USA) $125 \times 4.6 \mathrm{~mm}, 5$ $\mu \mathrm{m}$, octyl silica packing ( $\mathrm{Si}-[\mathrm{CH} 2] 7-\mathrm{CH} 3) \mathrm{C} 18$ (The carbon content is as much as $18 \%$. pH range for their stability is 1.5-9.0) and used for analysis. A Shimadzu AW220 electronic balance (Shimadzu Japan), James ultrasonic bath (James Products Europe Limited UK) and Millipore vacuum filtration assembly was also used in this work.

\section{Solution Preparation Mobile Phase}

In $1000 \mathrm{~mL}$ volumetric flask ammonium acetate $(0.8 \mathrm{~g})$ was dissolved in distilled water (500 $\mathrm{mL}$ ) to prepare ammonium acetate buffer solution. The $\mathrm{pH}$ of the solution was accommodated with $1.0 \%$ ammonia solution to $7.6 \pm 0.5$. Preparation of mobile phase was done by mixing ammonium acetate buffer $\mathrm{pH} 7.6$ and acetonitrile in the ratio $50: 50 \% \mathrm{v} / \mathrm{v}$ and filtered using a $0.22 \mu$ cellulose acetate Sartorius membrane filter using vacuum filtration assembly.

\section{Reference and sample stock solutions}

The efficacy and pureness of SFV reference standards was regulated by using $100 \mathrm{~mL}$ volumetric flask, stock solutions were prepared by dissolving SFV (equivalent to $100.0 \mathrm{mg}$ ) in acetonitrile $(50 \mathrm{~mL})$. Q.S volume is then make up with ammonium acetate buffer $\mathrm{pH}$ 7.6. A composite sample stock solution containing SFV $10 \mu \mathrm{gmL}^{-1}$ was prepared by diluting one millilitre of this solution with mobile phase using $100 \mathrm{~mL}$ clear glass volumetric flasks. $0.45 \mu$ cellulose acetate filter paper from Sartorius was used for filtration. The reference and sample stock solutions were protected from light, kept at $8-15{ }^{\circ} \mathrm{C}$, and extra diluted for synthesized and individual standard solutions whenever needed in method development and validation study.

\section{Experiments development}

SFV contains conjugated group and benzene ring in its structure, thus it is UV-active compound. Its maximum absorbance and the specific absorbance $(A=1 \%)$ is shown at $\lambda=262$ \pm 1 and $178.5 \pm 4$, respectively. The absorbance of separate and composite reference solution consist of SFV $10 \mu \mathrm{gmL}^{-1}$ was measured from 200 to 400 $\mathrm{nm}$ to obtain the optimal wavelength for the concurrent identification at a sole wavelength of the UV detector. HPLC analysis was performed on an LC-20AB (Shimadzu, Japan) with UV-VIS detector (Shimadzu, Japan) and a column oven. Agela C18 column (125 mm $4.6 \mathrm{~mm}, 5 \mu \mathrm{m}$ ) was used as analytical column. ZChrom software (version 4.2) processed the chromatographic data.

Reference solutions were interpret by isocratic elution of mobile phase with diverse proportions of mobile phase over column, i.e., octyl silica (Si-[CH2]7-CH3) C18. For both analyse, more appropriate resolution and symmetrical peaks were obtained in the aggregate of ammonium acetate buffer solution $(\mathrm{pH} 7.6)$ and acetonitrile $50: 50 \%(\mathrm{v} / \mathrm{v})$ at a flow rate of 0.5 $\mathrm{mL} / \mathrm{min}$ over $125 \mathrm{~mm} \times 4.6 \mathrm{~mm}, 5 \mu \mathrm{m} \mathrm{C18}$. The set of chromatographic conditions was else authorized according to USP and ICH guidelines. 


\section{Procedure}

The column was calibrated with the mobile phase for 30 minutes before the measurements; flipping through the chromatographic system so that the baseline noise shifts to minor i.e. $>0.5$ $\mathrm{mV}$ at detector gain 8. The standard/ sample solutions $(20 \mu \mathrm{L})$ were impregnated (two times) into the chromatograph under characterized environment.

\section{Results}

\section{System suitability}

USP guidelines were used to determine the suitability of system which consists of optimized conditions, i.e., merging of ammonium acetate buffer solution $\mathrm{pH} 7.6$ and acetonitrile 50:50 \% v/v as mobile phase at a flow rate of $0.5 \mathrm{~mL} / \mathrm{min}$ over Agela C18, $125 \mathrm{~mm} \times 4.6 \mathrm{~mm}, 5 \mu \mathrm{m}$. For peak response, ZChrom chromatography manager software version 4.2.was used to calculate the statistical data of different parameters like, retention time (tR), peak area (A) symmetry factor of SFV and theoretical plates (N) (Table 1). All the performance parameters of the analytical method obey and adhere to USP requirements for system suitability as shown in the results (Table 1). The RSD for analyse and tailing factor (As) were $<2.0$ $\%$ and the number of theoretical plates was $>2000$. The method was suitable for concurrent analysis of SFV and enforced strongly.

Table 1. System suitability parameters.

\begin{tabular}{llc}
\hline $\begin{array}{l}\text { Sr } \\
\text { No }\end{array}$ & Parameters & SFV \\
\hline 1 & Peak Area $(10 \mathrm{mcg} / \mathrm{mL})$ & 581075 \\
2 & Retention time & $2.3 \pm 2.505$ \\
3 & Theoretical plates & More then 2000 \\
4 & Asymmetry & $0.8 \% \pm 0.03$ \\
5 & Correlation $r$ & 0.9989 \\
6 & Slope & 6375.045 \\
7 & Intercept & -5063.266 \\
8 & LOD $\mu \mathrm{gmL}^{-1}$ & 0.245 \\
9 & LOQ $\mu \mathrm{gmL}^{-1}$ & 0.816 \\
\hline
\end{tabular}

\section{Linearity}

Different concentrations of sample solutions and their peak areas (by subjected to the chromatographic column) were used to plot the linearity curve. The results were linear (between a range of $10-6-\mu \mathrm{gmL}^{-1}$ with a regression equation of $y=6375.04 X-5063$ and $r^{2}=0.9989$.) as shown in Table 1 and (Fig. 1).

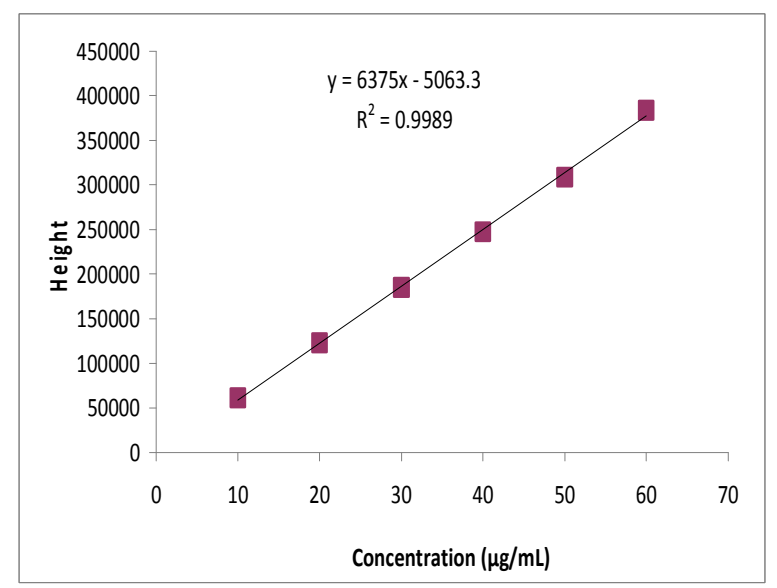

Figure 1. Calibration curve of standard material SFV

\section{Limit of detection}

Chromatograph was used to calculate the limit of detection optically. An array of dilution was prepared ranging from $10-60 \mu \mathrm{gmL}^{-1}$. At $0.245 \mu \mathrm{gmL}^{-1}$ LOD was observed.

\section{Limit of quantitation}

Chromatogram was used to determine the limit of quantitation (optically). An array of dilution was prepared ranging from 10-60 $\mathrm{gmL}^{-1}$. At $0.816 \mu \mathrm{gmL}^{-1}$ LOQ was observed. HPLC method was used for test repeatability.

\section{Inter-day repeatability}

The method precision was assessed by taking samples (in set of three) on inter at different time intervals. The average \% RSD was obtained as $0.722 \%$. Results are shown in Table 2 and Table 3. 
Table 2. Repeatability Analyses of $10 \mu \mathrm{gmL}^{-1}$ of SFV.

\begin{tabular}{lccc}
\hline Time $(\boldsymbol{h})$ & $\begin{array}{c}\text { Concent- } \\
\text { ration } \\
\left(\boldsymbol{\mu g m L ^ { - 1 } )}\right.\end{array}$ & $\begin{array}{c}\text { Retention } \\
\text { time } \\
(\text { min })\end{array}$ & Peak Area \\
\hline 0 & 10 & 2.292 & 581075 \\
1 & 10 & 2.262 & 581035 \\
2 & 10 & 2.282 & 581065 \\
4 & 10 & 2.299 & 591029 \\
6 & 10 & 2.281 & 583031 \\
8 & 10 & 2.292 & 579385 \\
\hline
\end{tabular}

Table 4. Repeatability Analyses of $20 \mu \mathrm{gmL}^{-1}$ of SFV.

\begin{tabular}{ccccc}
\hline Day & $\begin{array}{c}\text { Wavel- } \\
\text { ength }(\boldsymbol{n m})\end{array}$ & $\begin{array}{c}\text { Concent- } \\
\text { ration } \\
\left(\boldsymbol{\mu g m L ^ { - 1 } )}\right.\end{array}$ & $\begin{array}{c}\text { Retention } \\
\text { time } \\
(\boldsymbol{m i n})\end{array}$ & Peak Area \\
\hline 1 & 262 & 20 & 2.292 & 122510 \\
2 & 262 & 20 & 2.232 & 122659 \\
3 & 262 & 20 & 2.282 & 121921 \\
4 & 262 & 20 & 2.278 & 122670 \\
5 & 262 & 20 & 2.263 & 123020 \\
6 & 262 & 20 & 2.293 & 122613 \\
MEAN & & & 2.273 & 122565.5 \\
STANDARD DEVIATION & & 359.708 \\
\% RSD & & & & 0.6319 \\
\end{tabular}
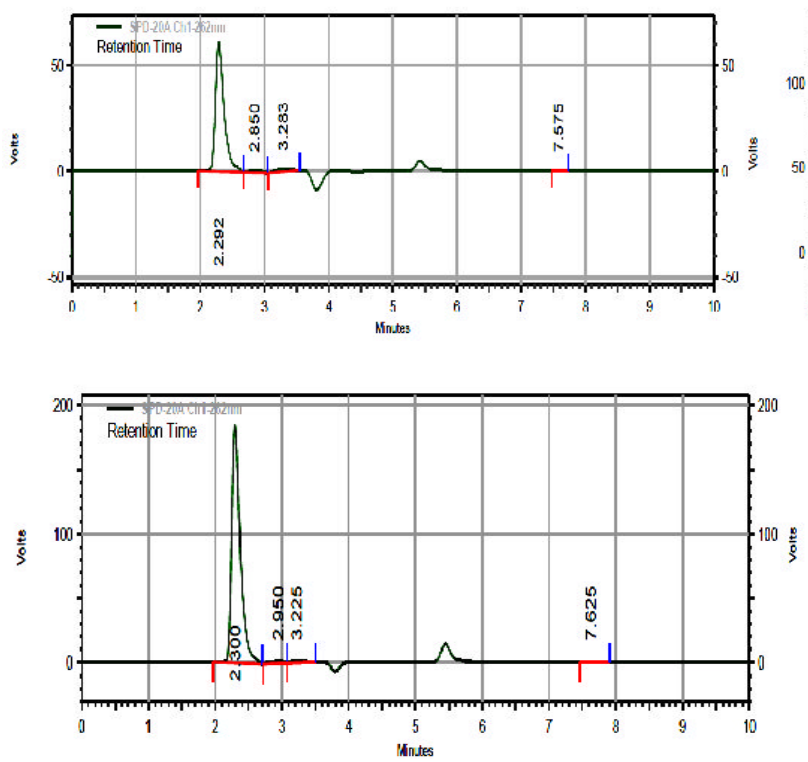

\section{Intra-day repeatability}

The intra-day precision of the HPLC method was investigated through $20 \mu \mathrm{gmL}^{-1}$ of test solution $(100 \%)$ by taking three determinations. In the analyses of Sofosbuvir raw material, $0.631 \%$ valus was obtained for the RSD for intraday $(n=6)$ precision.

\section{Accuracy and recovery}

In order to check the efficiency and accuracy of method; $10 \mu \mathrm{gmL}^{-1}$ of SFV was prepared at three \% age levels (120, 100 and $80 \%)$. At each concentration the inclusive recovery of SFV was $100 \pm 1$ and the RSD \% and RE \% of recovery studies were $<2.0 \%$.

Conc Recovery $=\frac{\text { Peak area of Sample }}{\text { Peak area of Stand }} \times \frac{\text { Conc of Stand }}{\% \text { Recovery }} \times 100$

Table 5. Accuracy test at three \%age levels of SFV.

\begin{tabular}{lccccc}
\hline $\begin{array}{l}\text { Assay } \\
\text { No }\end{array}$ & $\begin{array}{c}\text { Conc of } \\
\text { sample } \\
\%\end{array}$ & $\begin{array}{c}\text { Concent- } \\
\text { ration in } \\
\left.(\boldsymbol{\mu g m L})^{-1}\right)\end{array}$ & $\begin{array}{c}\text { Peak } \\
\text { area of } \\
\text { sample }\end{array}$ & $\begin{array}{c}\text { \%age } \\
\text { recovery }\end{array}$ & $\begin{array}{c}\text { \% } \boldsymbol{R S D} \\
(\boldsymbol{n}=3)\end{array}$ \\
\hline 1 & 80 & 8 & 464860 & 99.631 & 1.721 \\
2 & 100 & 10 & 581075 & 98.342 & 0.892 \\
3 & 120 & 12 & 697290 & 95.291 & 1.432 \\
\hline
\end{tabular}
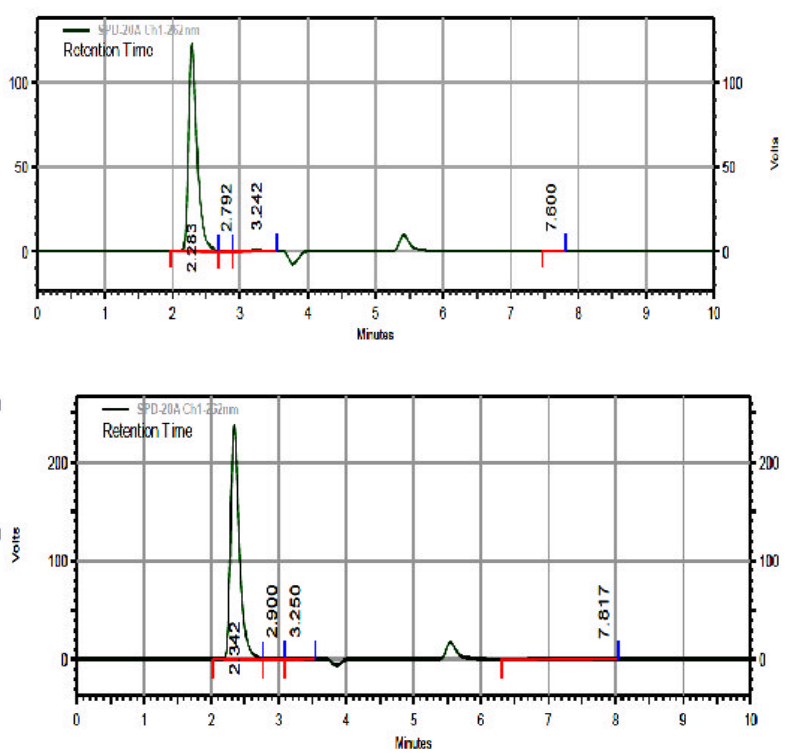


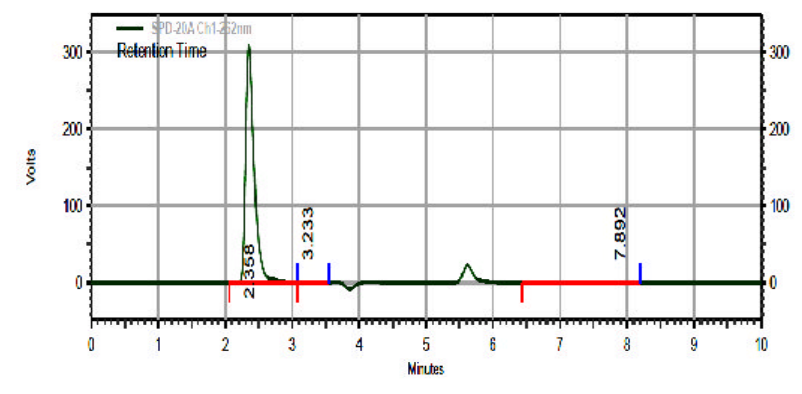

Figure 2. Standard chromatogram of different SFV concentrations

\section{Discussion}

The validation by HPLC has become an attractive and essential procedure because of its sensitivity and accuracy. The purpose of this study was to legitimize a swift, accurate and precise mechanism for elicitation of SFV from Bulk. An HPLC method was developed and correlated with the spectrophotometric procedures. Different concentrations of SFV $\left(10 \mu \mathrm{gmL}^{-1}\right.$ to $\left.60 \mu \mathrm{gmL}^{-1}\right)$ was used to prepare the standard solution as acetonitrile and ammonium acetate buffer ( $\mathrm{pH} 7.6)$ was used as the mobile phase in a ratio of 50:50.

A shimadzu HPLC machine (HPLC LC20AB) with Agela C18 column high resolution and a Column Length of $125 \mathrm{~mm}$ to $4.6 \mathrm{~mm}$, with a UV detector was used. At $262 \mathrm{~nm}$ wave length peak was taken. The sample was infused at a flow rate of $0.5 \mathrm{ml}$ per min. The run time of solvent was 8 minutes and for each sample the average retention time observed was 2.3 minutes. The fidelity was observed with the six replicate solutions on inter and intra days. Reproducible results were observed with all the chromatograms. The average \% RSD was $<2 \%$ (as shown in table). Theoretical plates were found to be unobjectionable i.e. $>2000$. Further recovery studies and three test assays confirmed the accuracy. Accuracy was in the range of $95-99 \%$ when checked at three \% age levels. LOD and LOQ was $0.245 \mu^{-1 m L}{ }^{-1}$ and 0.816 $\mu \mathrm{gmL}^{-1}$, respectively. The LOD and LOQ were evaluated optically using signal to noise ratio. The linearity range was $10-60 \mu^{-1}$ with six dilutions $(n=6)$. The regression equation of the curve and the $\mathrm{R}^{2}$ was $\mathrm{y}=6375.04 \mathrm{X}-5063$ and 0.998 , respectively by plotting concentration on $\mathrm{x}$ axis and peak area on y-axis.

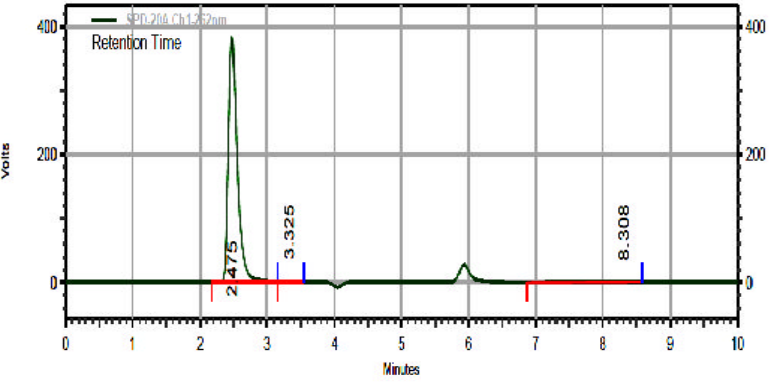

\section{Conclusion}

An economical, easy, accurate and precise RP-HPLC analytical method has been developed and validated for the quantitative analysis of sofosbuvir in crystalline form according to $\mathrm{ICH}$ gridline. This method is so simple when compared with reported methods. The lambda max of standard solution was observed at $262 \mathrm{~nm}$. Combination of acetonitrile and ammonium acetate buffer ( $\mathrm{pH}$ 7.6) was used to set the base line. Six dilutions $\left(10,20,30,40,50,60 \mathrm{\mu gmL}^{-1}\right)$ of $\mathrm{SFV}$ were prepared and the linearity curve was plotted. A linear range of $10-60 \mu \mathrm{gmL}^{-1}$ was observed with $\mathrm{R}^{2}$ value 0.998 which were respectable and in acceptable range.

\section{Conflict of Interest} interests

The authors declared no conflict of

\section{References}

1. D. Lavanchy, Clin. Microbiol. Infec., 17 (2011) 107.

https://doi.org/10.1111/j.14690691.2010.03432.x.

2. C. W. Shepard, L. Finelli and M. J. Alter, The Lancet Infect. Dis., 5 (2005) 558. https://doi.org/10.1016/S14733099(05)70216-4.

3. I. M. Jacobson, Clin. Gastroenterol. Hepatol., 8 (2010) 924. 10.1016/j.cgh.2010.06.032

4. T. Poynard and N. H. Afdhal, Antiviral Therapy, 15 (2010) 281. https://doi.org/10.3851/IMP1535. 
5. S. Naggie, K. Patel and J. McHutchison, $J$. Antimicrob. Chemoth., 65 (2010) 2063. https://doi.org/10.1093/jac/dkq284.

6. G. Magiorkinis, PLoS Comput. Biol., 9 (2013) e1002876. https://doi.org/10.1371/journal.pcbi.1002876.

7. B. L. Pearlman and N. Traub, Clin. Infect. Dis., 52 (2011) 889. https://doi.org/10.1093/cid/cir076.

8. M. G. Ghany, Hepatology, 54 (2011) 1433. https://doi.org/10.1002/hep.24641.

9. J. G. McHutchison, New England J. Med., 361 (2009) 580.

10.1056/NEJMoa0808010.
10. E. Cholongitas and G. V. Papatheodoridis, Ann Gastroenterol., 27 (2014) 331. https://www.ncbi.nlm.nih.gov/pmc/articles/P MC4188929/

11. G. M. Keating and A. Vaidya, Drugs, 74 (2014) 273.

https://doi.org/10.1007/s40265-014-0179-7.

12. L. Rose, Annals Pharmacotherapy, 48 (2014) 1019.

https://doi.org/10.1177/1060028014534194. 